\title{
A DIVISÃO SOCIOSSEXUAL E RACIAL DO TRABALHO NO CENÁRIO DE EPIDEMIA DO COVID-19: considerações a partir de Heleieth Saffioti
}

\author{
Claudia Mazzei Nogueira* \\ Rachel Gouveia Passos **
}

\begin{abstract}
No presente artigo objetivamos analisar os impactos da pandemia do vírus COVID-19 sobre a divisão sociossexual e racial do trabalho no cenário brasileiro. A partir das pesquisas desenvolvidas pela(o/a)s autor(o/a) s sobre o trabalho feminino, procurou-se destacar o trabalho doméstico e de cuidados compreendendo que esse é executado majoritariamente pelas mulheres negras e pobres. Nesse caminho, o texto está divido em duas partes: na primeira, propomos dialogar com Heleieth Saffioti - pioneira para a compreensão do lugar social da mulher no capitalismo - em torno do tema da divisão sociossexual e racial do trabalho e suas expressões na sociedade contemporânea; e, na segunda, problematizamos sobre os efeitos da epidemia do COVID-19 no mercado de trabalho brasileiro, dando ênfase às mulheres negras e ao trabalho feminino doméstico e de cuidado assalariado.
\end{abstract}

Palavras-chave: Trabalho. Mulheres Negras. COVID-19. Trabalho Feminino. Heleieth Saffioti.

\section{INTRODUÇÃO}

A divisão sociossexual e racial do trabalho não é um fenômeno que está restrito à realidade brasileira, ele faz parte dos pilares do modo de produção capitalista e tem expressões particulares nas formações sociais dos estados modernos. Para Hirata (2010), no que diz respeito ao trabalho feminino, é possível localizar em uma perspectiva internacional quais os paradoxos que envolvem o trabalho das mulheres na era da acumulação flexível. Quando tratamos da divisão sociossexual do trabalho - sem racializar as relações sociais - estamos fragmentando a análise, homogeneizando as mulheres e colocando-as nas mesmas condições. Isto significa que entre as próprias mulheres também ocorre uma hierarquização da distribuição dos poderes e dos acessos. Quan-

\footnotetext{
* Universidade Federal de São Paulo (UNIFESP).

Rua Silva Jardim, n. 136, Edifício Central. Cep: 11015-020. Santos - São Paulo - Brasil. mazzeinogueira@uol.com.br https://orcid.org/0000-0003-0130-7189

* * Universidade Federal do Rio de Janeiro (ESS/UFRJ). Avenida Pasteur, n. 250 (fundos). Urca. Cep: 22290-240. Rio de Janeiro - Rio de Janeiro - Brasil. rachel.gouveia@gmail.com

https://orcid.org/0000-0003-2267-0200
}

do Hirata (2004) trata do que chama de servidão voluntária, ${ }^{1}$ que está atrelada ao trabalho doméstico e de cuidados, executado ao longo da vida inteira pelas mulheres, a autora está se referindo à naturalização e essencialização das suas atribuições sociais.

Entretanto, Gonzalez (1984) nos mostra que os resultados da articulação entre o racismo e o sexismo resultam em efeitos violentos para as mulheres negras. A autora denuncia a naturalização da subalternização das mulheres negras, porque destina a esses corpos e subjetividades um determinado lugar social que é o da servidão. Só que essa servidão não é a mesma da mulher branca, pois, em grande medida foram retiradas das mulheres negras o direito da maternagem, da família, dos cuidados e ao seu próprio corpo (Giacomini, 1988).

Nesse sentido, podemos dizer que há uma simbiose entre a esfera produtiva e reprodutiva que faz com que a perpetuação dessa subalternização esteja presente no mundo do trabalho e nas relações sociais familiares, o que

\footnotetext{
${ }^{1}$ De acordo com Helena Hirata (2004), as mulheres são condicionadas a assumirem o trabalho doméstico e de cuidados no interior da família, tendo a afetividade como
} justificativa. 
leva aos acessos e oportunidades diferenciadas entre as mulheres. Torna-se fundamental afirmar que os processos sociais racializados destinam às mulheres negras funções e atribuições que são vinculadas à servidão. Podemos então identificar esse fenômeno no relato da professora e historiadora Luana Tolentino que denunciou nas redes sociais um episódio de racismo: ao caminhar pela rua foi abordada por uma senhora branca que perguntou se ela fazia faxina. ${ }^{2}$

Tal situação é extremamente comum na vida das mulheres negras. Tanto que no cenário da epidemia do COVID-19, são as mulheres negras aquelas que estão sofrendo mais intensamente seus grandes impactos, seja na contaminação e mortalidade, seja na regressão dos direitos. Em março de 2020, - momento em que escrevemos o presente artigo -, já haviam casos de domésticas que precisavam trabalhar na casa dos patrões contaminados. Portanto, nos cabe indagar: afinal, de quem é o "privilégio da servidão" no cenário contemporâneo ${ }^{3}$ ?

Nesse caminho, nas sessões seguintes, propomos dialogar com Heleieth Saffioti - autora considerada pioneira para a compreensão do lugar social da mulher no capitalismo - sobre a divisão sociossexual e racial do trabalho e suas expressões na sociedade contemporânea. Além disso, devemos problematizar acerca dos efeitos da epidemia do COVID-19 no mercado de trabalho brasileiro, dando ênfase às mulheres negras e ao trabalho doméstico e de cuidados.

\section{O QUE É A DIVISÃo SOCIOSSE-} XUAL E RACIAL DO TRABALHO?

¿. Quando realizamos uma análise que parte das relações de gênero e raça para compreen$>$

ฮิ 2 Disponível em: https://www.cartacapital.com.br/educacao/voce-faz-faxina-nao-faco-mestrado-sou-professora/. Acesso em 23/03/2020.

๘ ${ }^{3} \mathrm{O}$ professor Ricardo Antunes publicou em 2018 o livro "O privilégio da servidão: o novo proletariado de serviços na era digital” pela Editora Boitempo. Ao nos referirmos ao título do livro estamos problematizando sobre o perfil da população que ocupa os trabalhos precários e subalternos no Brasil, em especial aquelas que ocupam o trabalho doméstico e de cuidados. dermos os efeitos da divisão sociossexual e racial sobre o mercado de trabalho, identificamos uma grande desigualdade no que diz respeito à relação entre homens e mulheres e mulheres brancas e mulheres negras. Cabe assinalar que essas desigualdades resultam do racismo e do patriarcado, uma vez que ambos podem ser definidos como ideologias de dominação que compõem a formação social brasileira (Moura, 1994; Saffioti, 1976). Nesse sentido, destacamos que as relações sociais no Brasil foram constituídas e assentadas na exploração e desigualdade de classe e nas opressões de gênero e raça/etnia. (Passos; Nogueira, 2018).

Partimos da ideia de que a divisão sociossexual e racial estrutura as esferas produtivas e reprodutivas (duas dimensões fundamentais do ser social) sendo, em grande medida, determinante para a situação desigual entre os indivíduos já que subalternizou as mulheres em todo o processo histórico. Isto significa que a luta por uma divisão sociossexual e racial do trabalho mais justa refere-se, portanto, também ao enfrentamento do próprio capitalismo. Assim, cabe destacar que o patriarcado, a família e o casamento estão diretamente imbricados na esfera da reprodução, sendo uma construção social, cultural e histórica. Para Saffioti,

O patriarcado não se resume a um sistema de dominação, modelado pela ideologia machista. Mais do que isto, ele é também um sistema de exploração. Enquanto a dominação pode, para efeitos de análise, ser situada essencialmente nos campos político e ideológico, a exploração diz respeito diretamente ao terreno econômico (Saffioti, 1987, p.51).

\section{E complementa,}

Tanto a dona-de-casa, que deve trazer a residência segundo o gosto do marido, quanto a trabalhadora assalariada, que acumula duas jornadas de trabalho, são objetos da exploração do homem, no plano da família. Na qualidade de trabalhadora discriminada, obrigada a aceitar menores salários, a mulher é, no plano mais geral da sociedade, alvo da exploração do empresário capitalista. Desta sorte, fica patente a dupla dimensão do patriarcado: a dominação e a exploração (Saffioti, 1987, p. 51). 
Nesse sentido, a família patriarcal é parte intrínseca da dinâmica da sociedade capitalista. O trabalho doméstico, nos termos de Marx, não objetiva a criação de mercadorias, mas a criação de bens úteis para a reprodução dos próprios componentes da família, de futuros/as trabalhadores/as. Entretanto, no cenário atual o trabalho doméstico e de cuidados vem sendo mercantilizado pelo setor de serviços (Passos; Nogueira, 2018). Isto se deve ao fato de que na família patriarcal os papéis ditos masculinos e femininos não são produtos de um destino biológico, mas, eles são antes de tudo constructo sociais; que têm como bases materiais, o trabalho, a reprodução e os interesses do modo de produção capitalista. (Kergoat, s/d). Entretanto, a família patriarcal burguesa não é "destinada" a todos, assim, como o fato de ser mulher. Como herança do colonialismo, destinou-se aos homens e mulheres negros o lugar do "não-ser" (Fanon, 2008), ou seja, destituiu-lhes a humanidade e coisificou-se a existência negra.

A sociedade capitalista se utiliza dessa dinâmica de diferenciação com o intuito de hierarquizar as atividades e assim ampliar a exploração/opressão entre homens e mulheres e entre mulheres brancas e mulheres negras. Assim, a questão das relações de poder existentes, tanto na esfera da produção, quanto na esfera da reprodução, não pode ser evitada quando se fala da questão de igualdade, nem pode ser diluída na vaga noção de "igualdade de oportunidades" frente a sua evidente negação pela ordem social estabelecida. Assim, a igualdade substantiva não é de fato um objetivo do modo de produção capitalista, em verdade esta sociedade está repleta de contradições entre as quais Saffioti destaca três que são fundamentais: "a de gênero, a de raça/etnia e a de classe". Para a autora, o patriarcado ao longo da história foi "se fundindo com o racismo, e posteriormente, com o capitalismo, regime no qual desabrocharam, na sua plenitude, as classes sociais" (Saffioti, 2000, p. 73).

Com esta realidade o binômio explora- ção/opressão se torna latente para as mulheres (e toda a classe trabalhadora), todavia, especificamente em relação a elas, "o capitalismo teria aberto as portas do mundo do trabalho para a mulher. Não foi nem é assim. O capitalismo abriu as portas sim, mas do emprego, pois as mulheres já trabalhavam, havia muito tempo, mais que os homens" (Saffioti, 2000, p. 73). Entretanto, "ao se afirmar que sempre e em todos os lugares as mulheres se ocuparam do espaço doméstico, eliminam-se as diferenciações históricas" (Saffioti, 1987, p.11).

Seguindo com Saffioti, na relação de exploração/opressão presente na sociedade capitalista, existem três projetos, são eles: “o projeto da burguesia, que visa a dispor como lhe aprouver da classe trabalhadora; o projeto dos homens, cujo objetivo consiste em subordinar as mulheres; e o projeto dos brancos de manter sua supremacia, no caso do Brasil, face aos negros". Ou seja, no capitalismo brasileiro, o poder é da classe dominante, branca e masculina. (Saffioti, 2003, p. 37).

É verdade que esta realidade além de contemplar exploração, opressão e racismo, aliás, como frequentemente ocorre em todos os lugares onde os interesses do sistema do capital estão presentes, ainda se impõe um enorme peso sobre as mulheres pela manutenção da família nuclear, o que consequentemente altera sua situação no espaço produtivo. Em vez de se sentirem aliviadas, como pretenderia a retórica da "oportunidade e direitos iguais para as mulheres e da eliminação de qualquer discriminação de gênero e raça”, o que elas presenciam de fato é uma acentuada precarização da sua força de trabalho, sendo mais intensa quando se trata da mulher negra (Mészáros, 2002, p. 302-303).

Por isso é imprescindível que esteja presente na luta por uma divisão sociossexual e racial do trabalho igualitária, o combate da opressão masculina sobre a feminina, o combate ao racismo e à superação da relação de exploração do capital/trabalho. Além de que, "o gênero, a raça/etnicidade e as classes sociais constituem eixos estruturantes 
da sociedade”. Estes eixos, tomados isoladamente, apresentam características distintas daquelas que se pode detectar no nó que formaram ao longo da história. Eles "contém uma condensação, uma exacerbação, uma potenciação de contradições. Como tal, exige e merece tratamento específico, mesmo porque é neste nó que atuam, de forma imbricada, cada um" desses eixos (Saffioti, 2011, p. 78).

Deste modo, quanto mais profundas forem as "disfunções sociais" e o "nó ontológico: gênero, raça/etnia e classe” (Saffioti, 2011, p. 78), maior será a carga e as exigências impostas às mulheres; quanto mais acentuados forem esses pesos, além da exploração do seu trabalho no espaço produtivo, mais intensa fica a condição de opressão feminina no espaço reprodutivo patriarcal e racista.

Enfim, uma nova divisão sociossexual e racial do trabalho nas esferas produtivas e reprodutivas é profundamente necessária. No entanto, não é do interesse do capital uma metamorfose na divisão social, sexual e racial do trabalho em direção a uma igualdade substantiva e, tampouco, alterar a estrutura hierárquica presente na família patriarcal ou mesmo romper com a lógica racista, capaz de alcançar a tão almejada emancipação humana.

\section{MULHERES NEGRAS, DESIGUAL- DADES E OS IMPACTOS DO COVID-19}

Para analisar os impactos da pandemia do vírus COVID-19 sobre a divisão sociossexual e racial do trabalho, no cenário brasileiro, é necessário considerar que o ano de 2020 não começou muito bem no cenário internacional. No décimo primeiro dia do mês de março, a Organização Mundial de Saúde (OMS) decretou a existência de surto de pandemia devido à proliferação mundial do vírus COVID-19 que provoca doença causada por síndrome respiratória aguda (SARS-CoV-2). No Brasil, até o dia 4 de outubro de 2020, identificou-se 4.915.289 casos e 146.352 mortes, ${ }^{4}$ sendo que não se sabe ainda até quando ocorrerá a proliferação da doença no país. Ao longo dos meses de março e abril, o Ministério da Saúde e os governos estaduais e municipais indicavam o isolamento social da população como a principal estratégia de contenção da propagação da doença, além das orientações de higiene pessoal e das casas. Entretanto, como vivemos em um país que está assentado na desigualdade social e racial, nem todas as pessoas podem ficar isoladas em suas residências: por exemplo, em março de 2020, existiam 11,9 milhões de pessoas desocupadas o que representa $11,2 \%$ e $40,7 \%$ da população em situação informal, representando um contingente de 38,3 milhões de trabalhadores informais (IBGE, 2020), ${ }^{5}$ sendo que 6,4 milhões são trabalhadores domésticos.

A pandemia vem demandando respostas imediatas não apenas para a prevenção, tratamento e cura da doença, mas tem provocado a sociedade, os gestores e o Estado para uma maior atenção à população mais pobre que se encontra desocupada ou exercendo atividades na informalidade no mercado de trabalho. Com o isolamento social, ocorreu a suspensão dos transportes públicos, proibição de funcionamento de serviços não essenciais e estímulo à permanência em casa. Logo, trabalhadores/as domésticos/as informais acabam sendo atingidos diretamente, pois são dispensados e impedidos de trabalharem.

A informalidade é uma realidade persistente para as trabalhadoras domésticas como um todo: apesar do crescimento da formalização nas últimas duas décadas, ainda chegamos a 2018 com menos de 30\% da categoria com carteira de trabalho assinada - proporção que é ainda menor entre as trabalhadoras negras e que vem apresentando tendência de redução desde 2016, convertendo-se em um indicador a ser acompanhado de perto nos próximos anos (IPEA, 2019, p. 41).

${ }^{4}$ Disponível em: https://covid.saude.gov.br/ . Acesso em $04 / 10 / 2020$

5 Disponível em: https://agenciadenoticias.ibge.gov.br/ agencia-sala-de-imprensa/2013-agencia-de-noticias/releases/26978-taxa-de-desocupacao-e-de-11-2-e-taxa-de-subutilizacao-e-23-2-no-trimestre-encerrado-em-janeiro-de-2020. Acesso em 22/03/2020. 
É importante sinalizar que a proliferação da referida doença no país se deu, inicialmente, a partir de pessoas que viajaram para o exterior no período das férias de verão e no carnaval. Conforme publicado pelo Jornal $O$ Dia, ${ }^{6}$ na data de 22 de março, a cidade do Rio de Janeiro já apresentava mais de cem casos de pessoas contaminadas e notificadas com a doença no local considerado como o metro quadrado mais caro da cidade. Importante destacar que a primeira morte registrada no Rio de Janeiro foi de uma mulher de 63 anos que era trabalhadora doméstica no bairro do Leblon, e a patroa - que esteve na Itália - havia testado positivo para a doença. ${ }^{7}$ A senhora era idosa e moradora de uma cidade periférica - demorava mais de duas horas para chegar ao trabalho e por isso dormia no mesmo durante a semana - e morreu após contrair o vírus de sua empregadora que estava isolada em casa depois de retornar da viagem. Após o caso ganhar repercussão nas mídias sociais foi elaborado e divulgado um manifesto dos mais de 70 filhos e filhas de trabalhadoras domésticas de diferentes estados do Brasil que o enviaram às autoridades reivindicando dispensa remunerada das empregadas e diaristas pelos empregadores para que, assim, cumpram com as exigências de precaução no combate à propagação contagiosa do COVID-19. O manifesto recebeu apoio da Federação Nacional das Trabalhadoras Domésticas. ${ }^{8}$ Cabe destacar que segundo o IPEA (2019, p. 12), “6,2 milhões de pessoas, entre homens e mulheres, estavam empregadas no serviço doméstico, e destas, 3,9 milhões eram mulheres negras".

Portanto, a epidemia do COVID-19 tem revelado uma face perversa da desigualdade

6 Disponível em: https://odia.ig.com.br/rio-de-janeiro/2020/03/5886823-rio-tem-mais-de-100-casos-de-coronavirus--barra--ipanema-e-leblon-concentram-maioria.html\#foto=1. Acesso realizado em 22/03/2020.

${ }^{7}$ Disponível em: https://g1.globo.com/rj/rio-de-janeiro/noticia/2020/03/19/rj-confirma-a-primeira-morte-por-coronavirus.ghtml. Acesso realizado em 22/03/2020.

8 Disponível em: https://fenatrad.org.br/2020/03/20/fentrad-solicita-apoio-para-carta-manifesto-solicitando-dispensa-remunerada-para-a-categoria/. Acesso realizado em 22/03/2020. que atravessa o mercado de trabalho, ao explicitar o quanto o trabalho doméstico e de cuidados está assentado na divisão social, sexual e racial do trabalho. Se no período colonialista as mulheres negras eram castigadas e até mortas por desobedecerem às mulheres brancas na Casa Grande (Giacomini, 1983), no atual cenário passam fome ou morrem contaminadas pelo COVID-19 porque precisam trabalhar para sobreviver. ${ }^{9}$ Também, é importante sinalizar que a política de extermínio supostamente vigente não se revela apenas com os assassinatos da população negra ocasionados pelo braço penal do Estado, mas também se manifesta por meio do desemprego, pelas reformas trabalhistas e previdenciárias e pelo corte orçamentário nas políticas de saúde e educação. Por exemplo, no caso dos homicídios da população negra:

\begin{abstract}
[...] apenas em 2018, para citar o exemplo mais recente, os negros (soma de pretos e pardos, segundo classificação do IBGE) representaram 75,7\% das vítimas de homicídios, com uma taxa de homicídios por 100 mil habitantes de 37,8. Comparativamente, entre os não negros (soma de brancos, amarelos e indígenas) a taxa foi de 13,9, o que significa que, para cada indivíduo não negro morto em 2018, 2,7 negros foram mortos. Da mesma forma, as mulheres negras representaram $68 \%$ do total das mulheres assassinadas (IPEA, 2020, p. 47).
\end{abstract}

No que diz respeito especificamente às políticas de saúde e educação podemos destacar a Emenda Constitucional 95/ 2016 que limita os gastos públicos por vinte anos. Este congelamento dos investimentos nas políticas de saúde e educação, rebate diretamente sobre a população mais empobrecida, a qual acessa as políticas públicas. Cabe apontar que $80 \%$ da população brasileira que depende do Sistema Único de Saúde se autodeclara negra, ${ }^{10} \mathrm{O}$ que demonstra a perpetuação do que Mbembe (2018) denomina de necropolítica. ${ }^{11}$

${ }^{9}$ Para maior aprofundamento, buscar Preta-Rara (2019).

10 https:/www.geledes.org.br/quase-80-da-populacao-brasileira-que-depende-do-sus-se-autodeclara-negra/Acesso realizado em 08/09/2019.

${ }^{11}$ Necropolítica é um conceito desenvolvido pelo filósofo negro, historiador, teórico político e professor universitário camaronense AchilleMbembe que, em 2003, escreveu 
Entretanto, não é apenas com o acesso e as condições de cuidado em saúde que temos que nos preocupar. No que diz respeito à própria saúde da população, a ONU Brasil ${ }^{12}$ alerta que negros possuem maior incidência de problemas de saúde evitáveis no Brasil. Entre estes problemas, encontram-se: mortalidade de recém-nascidos antes dos seis dias de vida, infecções sexualmente transmissíveis, mortes maternas, hanseníase, tuberculose, diabetes tipo II e cardiopatia. Ou seja, os dados demonstram que o fato de não ter acesso a moradia digna, a uma alimentação adequada, e saneamento básico, vai acarretar um processo de adoecimento físico e, possivelmente psíquico.

Em relação ao mercado de trabalho, em especial o trabalho doméstico e de cuidados no Brasil, o IPEA (2019, p. 40) aponta que "as trabalhadoras domésticas representam o segundo maior grupamento ocupacional de mulheres no Brasil, ficando atrás apenas do comércio". Com algumas mudanças no regime de contratação das trabalhadoras domésticas, o IPEA (2019) considerou as diaristas ${ }^{13}$ em seu mapeamento, já que em 2018 correspondiam a 44\% da categoria, o que equivale a 2,5 milhões de mulheres. Portanto, apesar do envelhecimento da categoria, podemos afirmar que o trabalho doméstico ainda é uma opção para as mulheres negras e pobres.

Uma outra possibilidade de trabalho que é ocupada por mulheres negras é a de cuidadora de idosos. Entre os anos de 2007 e 2017, a ocuㄱ. pação passou de 5.263 para 34.051 profissionais خे empregados, tendo uma alta de $550 \%$, segundo 路 dados publicados pela Relação Anual de Infor-

um ensaio questionando os limites da soberania quando o Estado escolhe quem deve viver e quem deve morrer. O - ensaio virou livro e chegou ao Brasil em 2018, publicado

in pela editora $\mathrm{N}-1$. Para Mbembe, quando se nega a huma-

ळ nidade do outro qualquer violência se torna possível, de agressões até morte.

ثิ 12 https://nacoesunidas.org/negros-tem-maior-incidencia-de-problemas-de-saude-evitaveis-no-brasil-alerta-onu/ Acesso realizado em 08/09/2019.

ஸ ${ }^{13}$ Segundo o IPEA (2019, p. 40), as diaristas são "aquelas que, mesmo trabalhando em somente um domicílio, o fa-

zem por até 16 horas semanais" e "mesmo trabalhando em

\& um só domicílio, se os serviços só são prestados por dois

dias da semana, legalmente não há vínculo empregatício

nem obrigação por parte do empregador de assinar a car-

teira de trabalhar e pagar os encargos sociais". mações Sociais (RAIS), do Ministério do Trabalho. ${ }^{14} \mathrm{O}$ trabalho do cuidado não está restrito ao cuidado aos idosos, cabe salientar que pessoas com doenças crônicas e graves, crianças e pessoas em sofrimento psíquico grave, também necessitam de suporte para suprirem as necessidades da vida diária. Assim, podemos destacar que a política de saúde mental tem contratado cuidadoras para comporem as equipes de dispositivos que dão suporte às pessoas em sofrimento psíquico grave (Passos; 2018).

No período da epidemia do COVID-19, essas trabalhadoras sofreram com as restrições de circulação devido ao controle dos transportes públicos. No Rio de Janeiro houve restrição à circulação de pessoas que não comprovassem vínculo empregatício em serviços essenciais e/ ou autorizados para funcionamento. Contudo, para aqueles que trabalham de maneira informal, como é o caso da maioria das cuidadoras, tornou-se inviável chegar ao local de trabalho. A Associação de Cuidadores da Pessoa Idosa, da Saúde Mental e com Deficiência do Estado do Rio de Janeiro (ACIERJ) publicou uma nota aberta acerca do Decreto Estadual n 46980 de 19 de março, que trata sobre a circulação das pessoas, solicitando uma maior flexibilidade no que diz respeito às cuidadoras informais. Além disso, elaborou um documento que permitiu o embarque de cuidadoras de idosos sem comprovação empregatícia. ${ }^{15}$

Nesse caminho, desejamos chamar atenção sobre as desigualdades existentes no processo de propagação e morte ocasionado pela COVID-19 na realidade brasileira, o que vem sendo relativizado pelo bem-estar do mercado, dos bancos e da economia neoliberal. Como vemos, são as mulheres negras, pobres, faveladas, e suas famílias, as mais atingidas pela

14 Disponível em: https://www1.folha.uol.com.br/mercado/2018/12/cuidador-de-idosos-e-a-profissao-que-mais-cresce-em-10-anos.shtml. Acesso realizado em $23 / 03 / 2020$

15 Disponível em: https://coronavirus.rj.gov.br/cuidadores-de-idosos-que-nao-possuem-comprovacao-empregaticia-ja-podem-acessar-documento-que-permitira-o-embarque-nos-transportes-publicos/. Acesso realizado em: 23/03/2020. 
pandemia, uma vez que no momento em que escrevemos esse artigo temos registrado a primeira morte em favela. ${ }^{16}$

Em uma edição extraordinária do Diário Oficial da União, o presidente da república Jair Messias Bolsonaro publicou a medida provisória $n^{\circ}$ 927/2020 permitindo que os contratos de trabalho e salários fossem suspensos por até quatro meses no período de calamidade pública. Tal medida faz parte do conjunto de estratégias assumidas como tentativas para amenizar os efeitos econômicos da pandemia, sendo que mais uma vez a classe trabalhadora é quem paga o alto preço. Destacamos que o governo federal defendia a proposta como forma de evitar demissões em massa. No entanto, após muita crítica e oposição, no mesmo dia em que ocorreu a publicação da MP, o então presidente revogou o artigo 18 que continha a tal suspensão salarial, mas manteve a medida provisória contendo outras orientações também prejudiciais à classe trabalhadora, entre elas a permissão da demissão de trabalhadores/as. Mesmo após a retirada do artigo 18 e mantida a publicação dessa medida, diversas entidades e órgãos continuaram a se manifestar criticamente através de notas públicas. A Associação de Juízes pela Democracia (AJD) enviou uma nota se posicionando contrária à medida expedida pelo governo federal e sinalizou: "enquanto outros países buscam garantir a manutenção do emprego e a OIT manifesta-se salientando a importância da proteção social durante a pandemia, o governo brasileiro aproveita-se da crise sanitária para deflagrar mais um ataque aos direitos sociais trabalhistas". ${ }^{17}$ Vale lembrar que o presidente francês Emmanuel Macron apontou a necessidade de se rever alguns pontos da agenda do neoliberalismo considerando que a pandemia trouxe questões importantes para se repensar o mo-

${ }^{16}$ Disponível em: https://g1.globo.com/rj/rio-de-janeiro/noticia/2020/03/22/cidade-de-deus-tem-registro-de-paciente-com-coronavirus.ghtml. Acesso realizado em: 23/03/2020.

${ }^{17}$ Disponível em: https://ajd.org.br/noticias/2548-nota-publica-denuncia-contra-o-golpe-de-estado-em-curso-no-brasil. Acesso realizado em: 23/03/2020. delo vigente. ${ }^{18}$

Por fim, na noite do dia 24 de março, em horário nobre, o presidente da república realizou pronunciamento afirmando que há atitudes exageradas nas medidas tomadas por alguns governadores e prefeitos ao decretarem o isolamento social da população, além de dizer que o COVID-19 é apenas uma "gripezinha”. O presidente também afirmou que apenas os idosos devem ter cuidado e que está ocorrendo uma histeria coletiva. Após a repercussão desse pronunciamento diversas entidades, movimentos e órgãos da saúde manifestaram-se condenando o discurso do presidente. Tal posicionamento apenas reafirmou a necropolítica como a principal estratégia adotada por este governo, que além de realizar cortes nos benefícios e aposentadorias, sucatear o Sistema Único de Saúde e a política de Assistência Social, alega que a morte de pessoas é normal e estimula o retorno ao trabalho em nome da economia. Importante destacar que a Sociedade Brasileira de Infectologia emitiu uma nota sobre este pronunciamento reafirmando a necessidade do isolamento social e das medidas restritivas, e lembrando que os profissionais da saúde estavam trabalhando arduamente para minimizar a disseminação e cuidar daqueles que foram contaminados.

Portanto, deixamos a seguinte indagação: afinal, quem é que tem o "privilégio" da servidão e da morte? A resposta é simples e objetiva: a classe trabalhadora, em especial as mulheres negras e suas famílias.

\section{CONCLUSÕES}

Frente ao exposto em nossa reflexão, podemos afirmar que o modo de produção capitalista - considerando ambas as esferas da produção e reprodução social - associado ao patriarcado e ao racismo, constitui-se como responsável pelas desigualdades de gê-

${ }^{18}$ Disponível em: https://ajd.org.br/noticias/2548-nota-pu-
blica-denuncia-contra-o-golpe-de-estado-em-curso-no-brasil. Acesso realizado em: 23/03/2020. 
nero, raça e de classe. Como argumentamos, as mulheres se encontram inseridas, tanto na esfera produtiva como na reprodutiva, porém, no mundo do trabalho continuamos enquanto força de trabalho sub-remunerada, intensamente precarizada, e ocupando majoritariamente os trabalhos mais precários, como é o caso do trabalho doméstico e de cuidado assalariado. Isso ocorre justamente porque existe uma contradição da sua presença neste espaço: ao mesmo tempo em que o capital explora ao limite a sua força de trabalho, ele também necessita dessas mulheres no espaço reprodutivo para garantir a sua manutenção e reprodução.

Quando pensamos hoje no trabalho doméstico e de cuidado assalariado, vemos que há uma dimensão significativa da luta da mulher negra e pobre. E quando falamos de mulheres, prioritariamente as negras e desprovidas, constatamos que estas se encontram em situação de maior precarização e proteção social, como podemos constatar, por exemplo, nesta inesperada crise da saúde (e consequentemente da economia e política mundial), por conta da epidemia do Covid-19 (Sars-CoV-2). Isto reforça a perspectiva de que a formação social brasileira assentada no modo de produção capitalista mantém o seu interesse na desigual divisão sociossexual do trabalho, atingindo diretamente as questões de classe, gênero e raça/etnia.

No entanto, não impede que os interesses do modo de produção capitalista influenciem o aumento da precarização e desvalorização deste trabalho doméstico assalariado. Pois, o que permanece nesta realidade é a desigual divisão sociossexual e racial do trabalho, onde, ainda hoje, para os homens fica reservada a esfera do trabalho produtivo e as melhores posições hierárquicas deste. Já para as mulheres, a esfera que lhe condiz é a reprodutiva e quando esta se insere no trabalho produtivo, tendem a ocupar os extratos mais precários. Como vimos, se esta mulher for negra, esta realidade é ainda mais perversa, uma vez que é "coisifica- da" e por isso pode ser submetida a qualquer situação de trabalho precário.

Recebido em 20 de julho de 2020 Aceito em 05 de outubro de 2020

\section{REFERÊNCIAS}

ANTUNES, Ricardo. O privilégio da servidão: o novo proletariado de serviços na era digital. Editora Boitempo, São Paulo, 2018.

FANON, F. Peles negras, máscaras brancas. Editora UFBA, Salvador, 2008.

GIACOMINI, S.M. Mulher e Escrava: uma introdução histórica ao estudo da mulher negra no Brasil. Editora Vozes, Petrópolis, 1988.

GONZALES, L. Racismo e Sexismo na Cultura Brasileira. Revista Ciências Sociais Hoje, ANPOCS, p. 223-244, 1984.

HIRATA, H. Trabalho doméstico: uma servidão "voluntária"? In: GODINHO, T.; SILVEIRA, M.L. (orgs.). Políticas Públicas e Igualdade de Gênero. São Paulo: Coordenadoria Especial da Mulher, 2004, p.43-54.

HIRATA, H. Novas configurações da divisão sexual do trabalho. Revista Tecnologia e Sociedade, Curitiba,v. 6, n. 11, p.01-07, jul./dez. 2010.

IPEA. Os desafios do passado no trabalho doméstico do século XXI: reflexões para o caso brasileiro a partir dos dados da PNAD contínua. Textos para a discussão, IPEA, Brasília/ Rio de Janeiro, novembro, 2019, p.01-02.

Atlas da Violência 2020. Instituto de Pesquisa Econômica Aplicada. Brasília, p. 7-91, 2020.

KERGOAT, D. A relação social de sexo: da reprodução das relações sociais à sua subversão (s.d) (mimeo).

MBEMBE, A. Necropolítica. N-1 edições, São Paulo, 2018.

MÉSZÁROS, I. Para Além do Capital, Boitempo Editorial, São Paulo, 2002.

MOURA, C. Particularidades do racismo brasileiro. Revista Princípios, Natal, n. 32, p. 62-64, fev./abr., 1994.

PASSOS, R.G.; NOGUEIRA, C.M. O fenômeno da terceirização e a divisão sociossexual e racial do trabalho. Revista Katalysis, Florianópolis, v. 21, n. 3, p. 484-503, set./dez.2018.

PASSOS, R.G. Trabalho, Gênero e Saúde Mental: considerações para a profissionalização do cuidado feminino. Editora Cortez, São Paulo, 2018.

PRETA-RARA. Eu, empregada doméstica: a senzala moderna é o quartinho de empregada. Editora Letramento, Belo Horizonte, Minas Gerais, 2019.

SAFFIOTI, H. A mulher na sociedade de classes: mito e realidade. Petrópolis: Vozes, 1976.

. O Poder do Macho. São Paulo: Moderna, 1987.

Quem tem medo dos esquemas patriarcais de pensamento? Dossiê Crítica Marxista, 11, 7175, 2000.

Violência estrutural e de gênero: Mulher gosta de apanhar? Programa de Prevenção, Assistência e Combate à Violência Contra a Mulher - Plano Nacional: diálogos sobre violência doméstica e de gênero: construindo políticas públicas / Secretaria Especial de Políticas para as Mulheres. - Brasília: A Secretaria, 2003.

Gênero, patriarcado, violência. Editora Fundação Perseu Abramo, São Paulo, 2011. 


\section{THE SOCIOSEXUAL AND RACIAL DIVISION OF WORK IN THE EPIDEMIC SCENARIO OF COVID-19: considerations from Heleieth Saffioti}

\author{
Claudia Mazzei Nogueira \\ Rachel Gouveia Passos
}

\section{LA DIVISION SOCIOSEXUELLE ET RACIALE DU TRAVAIL DANS LE SCÉNARIO ÉPIDÉMIQUE DE COVID-19: considérations d'Heleieth Saffioti

\author{
Claudia Mazzei Nogueira \\ Rachel Gouveia Passos
}

In this article we aim to analyze the impacts of the COVID-19 virus pandemic on the socio-sexual and racial division of labor in the Brazilian scenario. Based on the research carried out by the authors on women's work, it was sought to highlight domestic and care work, understanding that it is performed mainly by black and poor women. In this way, the text is divided into two parts: the first where we propose to dialogue with HeleiethSaffioti - pioneer for the understanding of the social place of women in capitalism - on the sociosexual and racial division of labor and its expressions in contemporary society, and the second, we questioned the effects of the COVID-19 epidemic on the Brazilian labor market, emphasizing black women and female domestic work and wage care.

KEYwORDS: Work. Women. COVID-19. Female Work. HeleiethSaffioti.
Dans cet article, nous visons à analyser les impacts de la pandémie du virus COVID-19 sur la division socio-sexuelle et raciale du travail dans le scénario brésilien. Sur la base des recherches menées par les auteurs sur le travail des femmes, il a été cherché à mettre en évidence le travail domestique et de soin, sachant qu'il est principalement réalisé par des femmes noires et pauvres. De cette façon, le texte est divisé en deux parties: la première où nous proposons de dialoguer avec HeleiethSaffioti pionnière pour la compréhension de la place sociale des femmes dans le capitalisme - sur la división socio-sexuelle et raciale du travail et ses expressions dans la société contemporaine, et la seconde, nous nous sommes interrogés sur les effets de l'épidémie de COVID-19 sur le marché du travail brésilien, en mettantl'accent sur les femmes noires et le travail domestique féminin et les salaires.

Mots-ClÉs: Travail. Femmes. COVID-19. Travail féminin. HeleiethSaffioti. 
